\title{
Determination of Optimum Eri Silkworm Larvae Population Density in Feeding Tray using Shelf Rearing Technique
}

\author{
Tilahun A*, Terefe M, Shifa K and Ibrahim A \\ Ethiopian Institute of Agricultural Research Center, Melkassa Agricultural Research \\ Center, Ethiopia
}

*Corresponding author: Tilahun A, Ethiopian Institute of Agricultural Research Center, Melkassa Agricultural Research Center, Melkassa, Ethiopia, E-mail: abiyt2005@gmail.com

\author{
Research Article \\ Volume 2 Issue 4
}

Received Date: October 10, 2017

Published Date: October 23, 2017

\section{Abstract}

Population density during the different stages of larval growth and development is one of the crucial issues for successful commercial cocoon crop of silkworms. Using appropriate population density ensures the hygiene of silkworms in order to protect from disease infection and to ensure them good feeding appetite. Different stages of silkworm larvae require different population density or bed space during their growing period in the rearing bed. As worms increase in size, there is overcrowding and overlapping each other that leads to underfeeding, creating a microclimate for disease spread and could also lead to suffocation. Hence, appropriate bed spacing is essential to silkworm larvae, to keep them healthy and productive. The treatments used for examining the appropriate population density of young and medium aged silkworm larvae were 1200, 1000, 800, 600, 400 and 200 per feeding tray $(60 \mathrm{~cm} \mathrm{X} 90 \mathrm{~cm}$ size). Another arrangement of population density used for examining the mature aged silkworm larvae were 600, 500, 400, 300, 200 and 100 per feeding tray $(60 \mathrm{~cm}$ X $90 \mathrm{~cm}$ size) using silkworm shelf rearing technique to evaluate the effects of population density on different larval stages eri silkworm strains. $1^{\text {st }}$ and $2^{\text {nd }}$ larval instars/stages as young age, $3^{\text {rd }}$ and $4^{\text {th }}$ larval instars as medium age, $5^{\text {th }}$ larval instar as mature age were considered in the study. Observations on larval mortality, single larval weight, single shell weight, and silk ratio from different eri silkworm strains were carefully noted for each treatment and replications. Three replications were used for each treatment. Statistically significant variation in mean larval mortality rate among population densities was observed in young, medium and mature silkworm larval stages of silkworm strains. Larval mortality rate was significantly reduced when young, medium and mature larval stages of castor feeding eri silkworm strains (Indian eri and Vietnamese eri) reared in a group of 400 to 800 worms, 400 to 600 worms and 300 to 400 worms respectively in a $60 \mathrm{~cm} \mathrm{X} 90 \mathrm{~cm}$ feeding tray of shelf rearing method. Bigger Larval weight, bigger shell weight and higher percentage of silk ratio are important cocoon yield quality parameters for silkworm strains. Significant (P < 0.05$)$ variations were observed among population densities for these important variables in all the tested eri silkworm strains.

Keywords: Population density; Silkworm strains; Feeding tray; Larval instars; Larval mortality; Shell weight; Silk ratio 


\section{Open Access Journal of Agricultural Research}

\section{Introduction}

Sericulture' is an art and science of rearing silkworms to produce cocoons and silk. This activity, apart from the rearing of silkworms, also involves growing of feed plants for silkworms, reeling or spinning of silk yarn from cocoons, weaving the silk yarn and further processing it to produce the silk fabric. Sericulture is the process of obtaining the natural silk fiber through silk worm rearing, which can be practiced in varying agro-climatic conditions, and is suited to different production systems [1]. Ethiopia is granted with diversified climate, vegetation and topography. This is also true for diversified options of sericulture industry which are adopted on different vegetation (for feeding of silkworms) and different species of silkworms [2]. FAO (1976) [3] published that silk production is a highly profitable business enterprise that can produce good return from small portion of land where most of the land can be used for other food crops production. Further, the by-products also find uses ranging from fertilizers in rural areas to pharmaceutical industries. Thus, silk production has the potential to make a significant contribution to the economy of many countries where there is surplus labor, low-costs of production and a willingness to adopt new technologies [4].

The business holds a ray of hope at village level for Ethiopian citizen migrating to cities searching for jobs [5]. Rearing performance in silkworms is affected by ecological, biochemical, physiological and quantitative characters, which influence growth and development, quantity and quality of silk they produce in different geographical locations [6,7]. The success in silkworm rearing depends on the various factors including successful implementation of technological and managerial tools along with high yielding and best-suited feed plant varieties and silkworm strains [8]. Silkworm rearing starts from egg stage and terminating in adults laying eggs and dying their natural death. During this course, they pass through five larval instars $\left(1^{\text {st }}, 2^{\text {nd }}, 3^{\text {rd }}\right.$, $4^{\text {th }}$, and $5^{\text {th }}$ instars) intervened by four moults, cocoon and pupal stage [1]. Silkworm rearing effectively means the culturing of five larval instars with better management practices. During larval growth stage bed cleaning [9] and spacing is an important silkworm rearing process to ensure the hygiene in the immediate vicinity of silkworms in order to protect from disease infection and to ensure them good feeding appetite [10]. As soon as the larvae grow-up, the size increases in the rearing bed which ultimately cause changing atmosphere and favoring multiplication of pathogenic organisms such as protozoa, fungi, bacteria and viruses [11]. Hence, an appropriate larval population density should be done for good growth and feeding to protect them from fungal, bacterial and viral infections [11]. Diseases are the behavioral and physiological changes induced by pathogens in an organism [12]. If proper population density is not done according to larval ages it leads to various complications viz. ill health of larvae, disinterest of the larvae to feed due to unhygienic conditions, ultimately worms becomes weak and low in productivity [12]. Since they cause substantial financial loss to the silk producers, their prevention and control assumes utmost importance. Hence, appropriate larval population density is essential to keep the worms healthy and productive. Population density studies revealed that when larvae were densely populated more number of dead larvae was observed compared to sparsely populated once [13]. They further revealed that appropriate larval population density minimizes the larval mortality. Sakthivel (2004) [14] observed superior larval growth, development and higher cocoon production when eri silkworms were properly placed on feeding trays according to their age.

The silkworm culture adaptation is being practiced in a large scale on the leaves of castor with ideal larval population density to administer nourishment to all the worms simultaneously and thereby to secure uniform growth and development of the worms [15]. They further mentioned that next to feeding, spacing and bed cleaning is an equally important factors. It is necessary for the health and progress of the worms. Sharma et al., (1996) [16] also observed that silkworms at proper population density resulted in significantly higher larval weight, larval survival, cocoon weight, shell weight, shell ratio, pupal weight, rate of pupation, silk productivity, fecundity and egg hatching with lower larval and pupal durations than those raised under improper condition in farmers' practices. The present study was therefore conducted to determine stage wise population density of the eri silkworm strains reared at Melkassa sericulture laboratory. The study also sought to examine the effect of population density on larval mortality, larval weight and yield components of eri silkworm strains.

\section{Materials and Methods}

This study was carried out at Melkassa Agricultural Research Center (MARC), sericulture research laboratory in 2014 to 2016. As per the rearing recommendations of silkworms by Rajan and Himantharaj (2005) [8], the silkworm rearing room and equipments were cleaned, washed and disinfected with $2 \%$ formalin solution at the rate of $800 \mathrm{ml}$ per $10 \mathrm{~m}^{2}$ before the commencement of the experiment .The silkworm breeds were reared following shelf rearing techniques starting from brushing till cocoon spinning. Eri silkworms at larval stage were fed castor 


\section{Open Access Journal of Agricultural Research}

(Ricinus communis L.) four times a day with tender leaves until $2^{\text {nd }}$ instar, semi tender leaves to $3^{\text {rd }}$ and $4^{\text {th }}$ instar larvae and mature leaves to $5^{\text {th }}$ instar larvae. For each feeding tray equal amount of feeds from same feed plant variety were given. The grown up worms, after completing feeding during late fifth instar at their ripened stage (ready to spin silk) were picked and transferred on the mountages (equipment to provide support for cocoon formation) for spinning silk cocoons. Ripened silkworms were identified by their characteristics movement to the corners of the rearing beds, reduction in size and transparent yellow appearance. On the sixth to eighth day of spinning, the cocoons were harvested, counted and weighed [1]. The experiment was arranged in Completely Randomized Design (CRD) in three replications. Observations on larval mortality rate, larval weight and qualitative characters of the cocoon (cocoon shell weight and silk ratio) were recorded. Different eri silkworm strains Viz... Vietnamese eri and Indian eri were evaluated in the experiment. The treatments used for examining the appropriate population density of young and medium aged larvae were 1200, 1000, 800, 600, 400 and 200 silkworm larvae per feeding tray $(60 \mathrm{~cm} \mathrm{X} 90 \mathrm{~cm})$. Another arrangement of population density used for examining the appropriate population density of late or mature aged larvae were $600,500,400,300,200$ and 100 silkworm larvae per feeding tray $(60 \mathrm{~cm} \mathrm{X} 90 \mathrm{~cm})$ for silkworm shelf rearing technique. Complete randomized design with three replications was used for each treatment. Statistical analysis software (SAS) was used to analyze the data using analysis of variance (ANOVA) procedure. Least significant difference (LSD) was used for mean separation. Percentage proportions were calculated for larval mortality rate.

\section{Results}

\section{Effect of Population Density on Larval Mortality of Eri Silkworm Strains}

This study attempted to understand the effect of population density on mortality of young ( $1^{\text {st }}$ and $2^{\text {nd }}$ larval stages), medium (3 ${ }^{\text {rd }}$ and $4^{\text {th }}$ larval stages) and mature ( $5^{\text {th }}$ larval stage) of eri silkworm strains.

Indian eri-silkworm strains: Significant difference was observed in young, medium and mature larval stages interms of larval mortality rate through applying different population densities. In young larval stages significantly lower death rate $(0.354 \%$ to $0.583 \%)$ was observed when reared 400 to 800 larvae per feeding tray. Mortality rate was significantly reduced when 400 to 600 medium silkworm larval stages $(0.434 \%$ to $0.458 \%)$ and 300 to 400 mature silkworm larval stages (4.55\% to $5.7 \%)$ have been grown in a rearing bed of $60 \mathrm{~cm} \times 90 \mathrm{~cm}$ size. The study revealed that when 800 to 1200 medium stage worms are reared in one rearing bed, mortality rate was significantly higher $(1.65 \%$ to $2.52 \%)$ where as rearing more than 500 mature larval stages in one feeding tray significantly increased larval mortality rate (10.09\%).

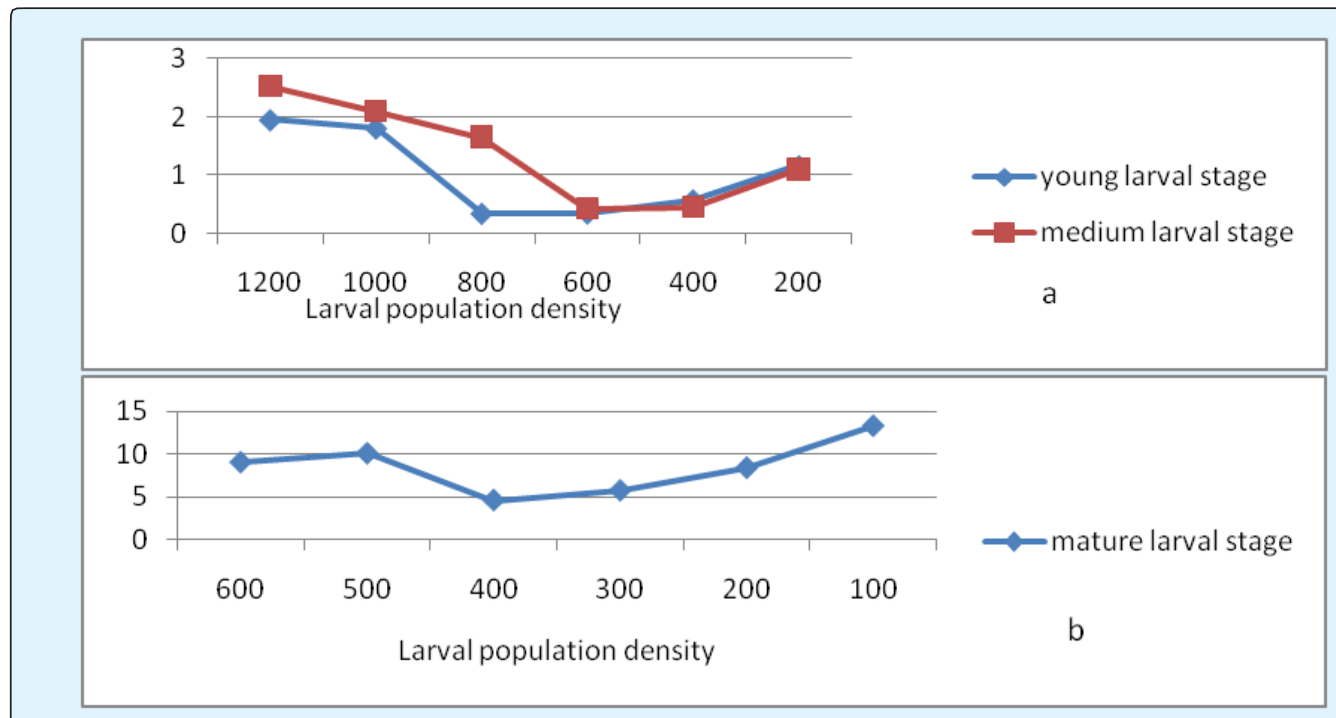

Figure 1: Effect of silkworm larvae population density on mortality of young, medium and mature larval stages of Indian eri-silkworm strains.

Vietnamese eri-silkworm strains: for young larval stages of this silkworm strain, larval mortality was significantly lower $(0.271 \%$ to $0.333 \%)$ in a population density of 400 to 800 worms as opposed to the other population densities which showed high larval death rate $(0.583 \%$ to $0.954 \%)$. For medium larval stages, larval mortality was significantly lower $(0.229 \%$ to $0.271 \%)$ in a population density of 400 to 600 worms when compared 


\section{Open Access Journal of Agricultural Research}

to the other population densities where by high larval death (up to $1.771 \%$ ) was recorded from other treatments. For mature larval stages, significantly lower rate of larval mortality ( $0.277 \%$ to $0.286 \%$ ) was obtained in a population density of 300 to 400 worms. Higher number of dead mature larvae was found from other treatments $(2.016 \%$ to $5.722 \%)$.

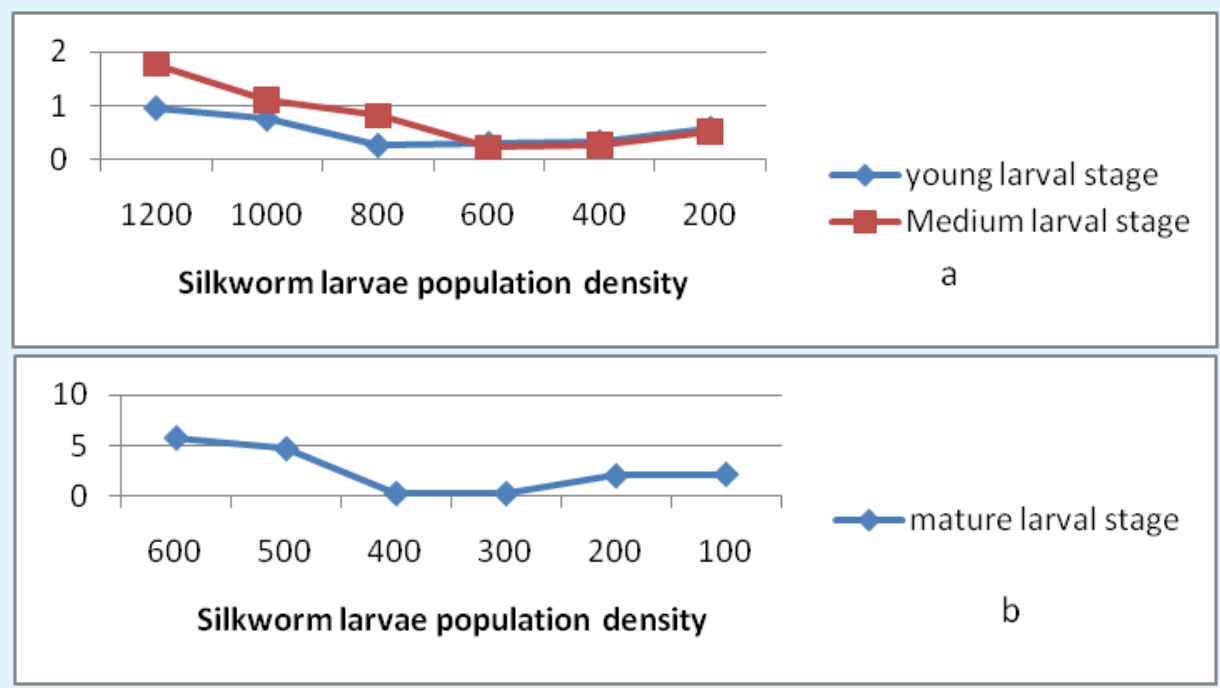

Figure 2: Effect of silkworm larvae population density on mortality of young, medium and mature larval stages of Vietnamese eri-silkworm strains.

Larval weight: larval weight was significantly $(\mathrm{P}<0.05)$ increased when 100 to 300 worms grown per feeding tray for Vietnamese eri silkworm strains (7.11 grams to 7.26 grams), when 100 to 400 worms grown for Indian eri silkworm strains (6.79 grams to 6.82 grams). The least larval weight for both silkworm strains was significantly obtained from a density of 500 to 600 larvae grown per feeding tray.

\begin{tabular}{|c|c|c|}
\hline population density & Vietnamese eri & Indian eri \\
\hline 600 & $4.85 \mathrm{~d}$ & $4.73 \mathrm{~d}$ \\
\hline 500 & $5.12 \mathrm{c}$ & $4.85 \mathrm{c}$ \\
\hline 400 & $5.37 \mathrm{~b}$ & $6.79 \mathrm{~b}$ \\
\hline 300 & $7.11 \mathrm{a}$ & $6.8 \mathrm{ba}$ \\
\hline 200 & $7.13 \mathrm{a}$ & $6.82 \mathrm{ba}$ \\
\hline 100 & $7.26 \mathrm{a}$ & $6.8 \mathrm{a}$ \\
\hline CV & 2.069 & 0.254 \\
\hline LSD & 0.231 & 0.028 \\
\hline
\end{tabular}

Table 1: Mean effects of silkworm larvae population density on larval weight (gm) of eri silkworm strains.

\section{Effect of Eri Silkworm Larvae Population Density on Qualitative Characters of the Cocoon of Silkworm Strains}

In this study qualitative traits of the silk cocoon (silk shell weight and silk ratio) were also evaluated to the different population density treatments. Table 2 summarizes the mean values of qualitative characters of the silk shell weight and silk ratio after the $5^{\text {th }}$ larval instar was treated to the different population densities.

This study revealed that there was statistically significant difference in shell weight and silk ratio among population densities in all silkworm strains (Table 2). Shell weight were significantly $(\mathrm{P}<0.05)$ increased when 100 to 300 worms reared per feeding tray for Vietnamese eri silkworm strains $(0.430 \mathrm{~g}$ to $0.477 \mathrm{~g})$ and for Indian eri silkworm strains $(0.387 \mathrm{~g}$ to $0.397 \mathrm{~g})$. Shell weight obtained from other treatments (400 to 600 worms) was significantly lower for both strains. A significant small shell weight was recorded in both silkworm strains while placing 600 worms in one feeding tray (silk worm bed).Silk ratio was significantly increased $(12.2 \%$ to $13.4 \%$ ) in 100 to 300 population density for Vietnamese eri silkworm strains. Lower percentage of silk ratio was registered from other treatments (400 to 600 worms) for the same strain. For Indian eri silkworms, higher percentage of silk ratio (11.3\% to $11.67 \%$ ) was found from a group of 100 to 400 worms in a feeding tray and lower percentage of silk ratio $(9.69 \%$ to $9.82 \%)$ was recorded from a group of 500 to 600 worms in a feeding tray. 


\section{Open Access Journal of Agricultural Research}

\begin{tabular}{|c|c|c|c|c|}
\hline \multirow{2}{*}{ Population density } & \multicolumn{2}{|c|}{ Vietnamese eri silkworm strains } & \multicolumn{2}{c|}{ Indian eri silkworm strains } \\
\cline { 2 - 5 } & Silk shell weight (grams) & Silk ratio (\%) & $\begin{array}{c}\text { Silk shell weight } \\
\text { (grams) }\end{array}$ & Silk ratio (\%) \\
\hline 600 & $0.320 \pm 0 \mathrm{~d}$ & $9.737 \pm 0.13 \mathrm{c}$ & $0.303 \pm 0.003 \mathrm{c}$ & $9.823 \pm 0.099 \mathrm{~b}$ \\
\hline 500 & $0.333 \pm 0.08 \mathrm{~d}$ & $9.953 \pm 0.30 \mathrm{c}$ & $0.307 \pm 0.003 \mathrm{c}$ & $9.693 \pm 0.039 \mathrm{~b}$ \\
\hline 400 & $0.373 \pm 0.012 \mathrm{c}$ & $10.537 \pm 0.38 \mathrm{c}$ & $0.367 \pm 0.008 \mathrm{~b}$ & $11.300 \pm 0.229 \mathrm{a}$ \\
\hline 300 & $0.430 \pm 0.010 \mathrm{~b}$ & $12.197 \pm 0.24 \mathrm{~b}$ & $0.387 \pm 0.013 \mathrm{a}$ & $11.593 \pm 0.406 \mathrm{a}$ \\
\hline 200 & $0.450 \pm 0.005 \mathrm{ba}$ & $12.927 \pm 0.14 \mathrm{ba}$ & $0.390 \pm 0.010 \mathrm{a}$ & $11.673 \pm 0.452 \mathrm{a}$ \\
\hline 100 & $0.477 \pm 0.008 \mathrm{a}$ & $13.413 \pm 0.24 \mathrm{a}$ & $0.397 \pm 0.008 \mathrm{a}$ & $11.657 \pm 0.258 \mathrm{a}$ \\
\hline CV & 3.944 & 4.239 & 2.926 & 3.296 \\
\hline LSD & 0.028 & 0.884 & 0.019 & 0.657 \\
\hline
\end{tabular}

Table 2: Mean effects of silkworm larvae population density on silk shell weight (grams) and silk ratio (\%) of eri silkworm strains.

\section{Discussion}

The success of sericulture industry depends upon several factors of which the impact of the silkworm management practices is of vital importance. Among the management practices, silkworm larvae population density plays a major role on growth and productivity of silkworm [17]. Literatures stating that good quality cocoons are produced through applying an appropriate silkworm population density and significant deviations from these levels make the cocoon quality poorer. In the present study, performance of silkworm strains was tested in different population density which generally proved a minimum and maximum population density in a range of 400 to 800 worms for young larval stages, 400 to 600 worms for medium larval stages, 300 to 400 worms for mature larval stages respectively. The different silkworm population density showed statistical significant differences among themselves in terms of important silkworm characters and silkworm mortality rate at $p<0.05$. Related studies conducted by Shah et al. (2007) [18], showed variations in the performance of silkworms at different population density levels. Moreover, significant variability among different population density levels on silkworm mortality $(0.056 \%$ to $15.33 \%$ ) were recorded which was also in conformity with Qader et al. (1992) [19] who observed such differences among groups of population density through mortality rate studies. In regard to cocoon parameters, this study showed variations in single shell weight $(0.303$ grams to 0.477 grams), and silk ratio (9.73 to $13.14 \%)$ ) in castor feeding silkworms. This result is in agreement with findings of Nguku et al (2009) [20] who studied performance of different silkworm strains at different population density levels. In general, all differences could be justified because rearing performance in silkworms is affected by silkworm population density which influence growth and development, quantity and quality of silk they produce in different geographical locations [6,7,21]. Among silkworm management determined factors,
Scriber and Slansky (1981) [22] stated that larval population density in the range of 400 to 1000 worms for young larval stages, 400 to 600 worms for medium larval stages, 300 to 500 worms for mature larval stages depending on eri silkworm breeds are required for effective growth and cocoon productivity. It is known that the productivity of silkworms is affected by larval population density or bed spacing and is verified in the silkworm strains reared. In addition, the silkworm mortality rate and silk cocoon traits vary to contribute to variability in performance of silkworm strains at different groups of population density [23]. Sannappa et al., (1999) [11] reported that as soon as the larvae grow-up, its size increases in the rearing bed which ultimately causes feed competition and suffocation. They further mentioned that due importance towards good silkworm management practices in and around the rearing house are a prerequisite for a successful cocoon harvest and ideal rearing condition such as bed spacing should be done as per the different instars of larval stages and silkworm breeds. This study also confirmed there was variability in larval mortality rate at young, medium and mature silkworm larvae of different silkworm strains in respective with various population density treatments. The results showed that using un ideal population density caused significant mortality rate due to suffocation and feed competition in both silkworm strains. Rearing under better feeding, bed cleaning and bed spacing ensuring pathogen free rearing conditions are some of the vital requirements for the growth of healthy worms. This enables the silkworm tolerate adverse conditions. Using appropriate population density/bed spacing according to larval size and weight ensures good bed hygiene, prevention of diseases and good larval growth [11]. Devaiah et al., (1985) [24] reported that feeding, spacing and cleaning are important silkworm management practices affecting the larval weight, silk gland weight, cocoon weight and shell weight considerably. In our study the cocoon characters after the $5^{\text {th }}$ instar was treated in different population density treatments providing 


\section{Open Access Journal of Agricultural Research}

supportive evidence for good rearing condition, also statistically significant among the tested population densities/bed spacing on many parameters.

Larval population density experiment revealed that some treatments were statistically superior in terms of minimum larval mortality, bigger larval weight, bigger silk shell weight and highest silk ratio depending on the successive larval stages of silkworm strains (Figures 1 and 2, Tables 1 and 2). After successful silkworm rearing such as ideal bed spacing, cocoon weight gain was recorded in previous findings. This difference in shell weight gain may be attributed to the difference in the bed spacing treatments selected for the study (Table 2). Results from our study revealed that variations in larval mortality rate, larval weight, shell weight and silk ratio were obtained in the treatments in both silkworm strains. The findings of our study are in agreement with those of Hajarika et al., (2003) [25]. They found that higher effective rate of rearing, cocoon weight, shell weight and shell ratio were achieved using ideal bed spacing treatments. This was achieved by integration of not a single but a multitude of approaches viz. proper disinfection of the rearing room and appliances, use of bed disinfectant as per recommendations [8], bed cleaning [9] and feeding [26]. Prevention is better than Cure" is the correct approach and that should be adopted in integrated silkworm rearing management [27]. This means that one should go about actively providing good silkworm management practices before any problem occurs, and it is only when preventive measures are in force that we can hope to effectively increase silk production and productivity.

Patil et al., (2009) [28] observed that silkworms receiving ideal management practices such as bed spacing, bed cleaning and feeding showed significantly higher larval weight $(7.904 \mathrm{~g})$, effective rate of rearing (90.0\%), shell weight (0.476 g), shell ratio (13.31\%), with lower larval and pupal durations in castor feeding silkworms. In Our study results indicating that the maximum shell weight ( $0.477 \mathrm{~g})$ and silk ratio (13.41\%) have been obtained in castor feeding silkworms' shelf rearing method. Devaiah et al., (1985) [24] reported that feeding, bed spacing and bed cleaning are important worm management practices affecting the larval weight, silk gland weight, cocoon weight and shell weight considerably. According to them maximum larval weight $(7.6 \mathrm{~g})$, effective rate of rearing $(92.0 \%)$, shell weight $(0.44 \mathrm{~g})$ and silk ratio $(14.9 \mathrm{~g})$ has been obtained in shelf method of rearing.

\section{Conclusion}

Bed spacing or population density during the larval growth at different stages is one of the crucial issues for successful cocoon crop of silkworm strains. The silkworm strains studied differ in their optimum larval population density requirements during their growth. Statistically significant variation in mean larval mortality rate and silk cocoon traits among population densities was observed in young, medium and mature silkworm larval stages. Different stages of silkworms require different bed space. Overcrowding of medium and mature silkworm larvae in a rearing bed/tray leads to underfeeding, creating a microclimate for disease spread and could also lead to suffocation. The larval development will be maximum during the $5^{\text {th }}$ Instar after $4^{\text {th }}$ moult. Too much crowd in the rearing tray results in increase in humidity, heat, fermentation of litter which results in un-hygienic conditions, wastage of leaf and under development of silkworm while sparse or low population of young silkworm larvae in a rearing bed/tray is loss of space. So, appropriate spacing should be given simultaneously at the time of bed cleaning or feeding and care should be taken not to disturb the worms very frequently.

\section{References}

1. Singh KC, Benchamin KV (2002) Biology and ecology of the eri silkmoth Samia ricini Donovan (Saturniidae): Bullet Ind Acad Seric 6(1): 20-33.

2. Metaferia HY, Amanuel T, Kedir S (2006) Scaling up of silk production technologies for employment and income generation in Ethiopia. Proceedings of the International Conference on Scaling Up and Scaling Out of Agricultural Technologies in Ethiopia, May 911, Ethiopian Institute of Agricultural Research, Addis Ababa, Ethiopia.

3. FAO (1976) Agricultural service Bulletin (15/1). Sericultural manual 1: Mulberry cultivation. Rome, Italy.

4. Hajare TN, Jadhav AD, Venugopalan M, Patil NG, Chaturvedi A, et al. (2007) Evaluation of sericulture for augmenting agricultural income of marginal farmers in semi-arid region of India. Proceedings of the International Conference on Sericulture Challenges in the $21^{\text {st }}$ Century and the 3rd BACSA Meeting, Vratza, Bulgaria, pp 18-21. 


\section{Open Access Journal of Agricultural Research}

5. Krishnaswami S (1978) New Technology of Silkworm Rearing. Bull Cent Seric Res Train Inst Mysore, pp 124.

6. Virk JS, Kaur L, Singh B (2011) Evaluation of different strains of mulberry silkworm and eri silkworm for the development of sericulture in Punjab. Int J agric Sci 7(2): 266-269.

7. Ramesha C, Lakshmi H, Kumari SS, Anuradha CM, Kumar CS (2012) Nutrigenetic screening strains of the mulberry silkworm, Bombyx mori, for nutritional efficiency. J Insect Sci 12: 1-18.

8. Rajan RK, Himantharaj MT (2005) Silkworm Rearing Technology. Central Silk Board, Bangalore, pp. 15136.

9. Abiy Tilahun, Kedir Shifa, Ibrahim A, Terefe M (2015) Study on silkworm bed cleaning frequency during larval developmental period. Science, Technology and Arts Research Journal 4(2): 39-47.

10. Gogoi B, Goswami BC (1998) Studies on certain aspects of wild eri silkworm (Philosamia cynthia Drury) with special reference to its rearing performance. Sericologia 38: 465-468.

11. Sannappa B, Jayaramaiah J (1999) Mineral Constituents of Selected Genotypes of Castor, Ricinus communis L. Mysore Journal of Agriculture Science 33: 157-161.

12. Aruga $H$ (2001) Principles of sericulture. $3^{\text {rd }}$ (Edn.) Oxford \& IBH publishing Co. Pvt. Ltd., New Delhi. Pp. 267-270.

13. Zhang YH, Xu AY, Wei YD, Li MW, Hou CX, et al. (2002) Studies on feeding habits of silkworm germplasm resources for artificial diet without mulberry. Acta Sericologia Sinica 28: 333-336.

14. Sakthivel N (2004) Eri culture on castor and tapioca in Tamil Nadu. In: Proceeding on workshop of prospects and development of ericulture, University of Agricultural Sciences, Dharwad pp 78-81.

15. Nangia N, Jagadish PS, Nageshchandra BK (2000) Evaluation of the Volumetric Attributes of the Eri Silkworm Reared on Various Host Plants. Int J Wild Silkmoth \& Silk 5: pp 36-38.

16. Sharma RK, Dutta SK, Bhuyan C (1996) Effect of Food Plants on Certain Life Parameters of Eri Silkworm (Philosamia ricini). Journal of Applied Biology 6(1-2): 115-120.
17. Benchamin KV, Jolly MS (1986) Principles of silkworm rearing. Proceedings of Seminar on Problems and Prospects of Sericulture, Mahalingam S (Ed.) Vellore, India, pp 63-106.

18. Shah SI, Khan Z, Hussain SM, Usman A, Sadozai A (2007) Studying the performance of silkworm, Bombyx mori L., races fed with different varieties. Sarhad J Agric 23(4): 1079-1083.

19. Qader MA, Haque R, Absar N (1992) Nutritive effects of different types of mulberry leaves on larval growth and cocoon characteristics of Bombyx mori L Pak J Zoology 24: 341-345.

20. Nguku EK, Adolkar VV, Raina SK, Mburugu KG, Mugenda OM, et al. (2009) Performance of Six Bivoltine Bombyx mori (Lepidoptera: Bombycidae) Silkworm Strains in Kenya. Th Op Entomol J 3: 1-6.

21. Reddy DNR, Kotikal YK, Vijayendra M (1989b) Development and Silk Yield of Eri Silkworm, Samia Cynthia ricini (Lepidoptera: Saturnidae) as Influenced by the Food Plants. Mysore Journal of Agriculture Science 23: 506-508.

22. Scriber JM, Slansky JF (1981) The nutritional ecology of immature insects. Annual Review of Entomology 26: 183-211.

23. Jayaramaiah M, Sannappa B (1998) Correlation coefficients between foliar constituents of castor genotypes and economic parameters of the eri silkworm, Samia cynthia ricini, Boisduval (Lepidoptera: Saturniidae). Proceedings of the 3rd International Conference on Wild Silkmoths, November, Bhubaneshwar, India, pp 11-14.

24. Devaiah MC, Gouda RR, Suhas Y, Govindan R (1985) Growth and Silk Production in Samiya cynthia ricini Boisduval (Lepidoptera: Saturniidae) Fed on Four Different Host Plants. Indian Journal of Sericulture 24: 33-35.

25. Hajarika U, Barah A, Phukan JC, Benshamin KV (2003) Study on the effect of different food plants and seasons on the larval development and cocoon characters of silkworm Samia cynthia ricini Boisduval. Bulletin of the Indian Academy of Sericulture 7: 77-85.

26. Ibrahim A, Tilahun A, Terefe M, Shifa Kedir (2017) Feed consumption rate and feeding frequencies of Eri and Mulberry silkworm at Melkassa Agricultural Research Center, Ethiopia. Acad Res J Agri Sci Res 5(1): 20-26. 


\section{Open Access Journal of Agricultural Research}

27. Nataraju B, Sathyaprasad K, Manjunath D, Kumar CA (2005) Silkworm Crop Protection. Central Silk Board, Bangalore. Pp: 412.
28. Patil RR, Kusugal S, Ankad G (2009) Performance of eri silkworm, Samia cynthia ricini Boisd on few food plants. Karnataka Journal of Agriculture Science 22: 210-221. 